Advances in Radio Science (2004) 2: 265-268

(C) Copernicus GmbH 2004

\title{
Sixty years of ionospheric measurements and studies*
}

\author{
K. Bibl \\ Center for Atmospheric Research, University of Massachusetts Lowell, 600 Suffolk St., Lowell, MA 01854-3625, USA \\ * Dedicated to Prof. Dr. K. Rawer on the occasion of his 90th birthday.
}

\begin{abstract}
Professor Rawer's professional ethics allowed him to create an excellent institute with co-workers forming a successful team with creative individuals. Showing myself as an example, this paper demonstrates his guidance, his care, and his ability to create independent thinking in the areas of equipment development and the analysis of data produced by this equipment.
\end{abstract}

\section{Introduction}

As one of the first co-worker of Professor Karl Rawer, I want to emphasize the beginning of my relationship with him and the influence he had on me. His philosophy was "die Treue im Kleinen", which I did not understand then. Now I believe that this philosophy can be found in one of my early teacher's, Werner Heisenberg, actions, in contrast with the hate of Edward Teller. One of Rawer's actions during the war was to send a co-worker, suspected to be Jewish, to a field-station in Sicily, where he was considered safe.

Instead of promoting himself in the middle of the war, he nominated me, a young student in uniform, for a national prize, which I received for designing the first pulse receiver (Huber and Rawer, 1950). But, what would Karl Rawer do with a soldier who, after the conspiracy on Hitler's life in 1944, refused to say "Heil Hitler" in the morning, but said "Grüss Gott" instead (although the guy did not believe in God). I was that guy; in order to protect me from prosecution, Karl Rawer sent me to a farmhouse in the western part of Austria to set up a new field site. There I finished a double receiver with common oscillator for installation in an Adcock direction finding system.

After the war, although I had established a successful business, I was forced out of Austria. Karl Rawer found a place for me to stay in Bavaria and feed my family successfully by repairing radios. With his perfect mastery of the

Correspondence to: $\mathrm{K}$. Bibl

(k.bibl@verizon.net)
French language, he boldly approached the Headquarter of the French Occupation Forces, persuading them to found the first French-German research institute. There he was able to reassemble many of his former co-workers; even managing to get one released from a prisoner-of-war camp.

\section{Ionosphären-Institut Breisach}

Karl Rawer had outstanding relations with his co-workers. Because of his multi-faceted skills in technology, mathematics, physics, and management, he liked to work with different people for joint research. But he also allowed most of them to do independent studies, leading to single-author publications. From the first publications of the institute between 1947 and 1960, 25\% were under his sole authorship, 28\% were jointly authored with some of his co-workers, but $47 \%$ were published with only his co-workers names. (Most were single author names.)

With me, he sometimes had a problem, because I thought I knew better in engineering. But he allowed me to prove my point in building the proto-type of the Panorama-Ionosonde (1/2 or 2 min ionograms) in the workshop after normal working hours. The Panorama-Ionosonde was based on an idea, which everybody thought was crazy. Instead of the bulky drums with bulky springs and switches, it had a single axle. On this axle three rotors of a variable capacitor, forming a 120-degree angle each, were mounted to cover three frequency bands. For independent tuning of the receiver input, the oscillator, and the synthesized transmitter, three of these sets of rotors, but also the respective inductors, were installed on the same axle. This is shown in Fig. 1. The silver coal contact with a silver ring, divided into three parts, formed also the band-switch. The oscillator rotors had different shapes for each band to allow perfect tuning for all frequencies. This Panorama-Ionosonde was built for many stations and was especially useful for measurements during solar eclipses. 


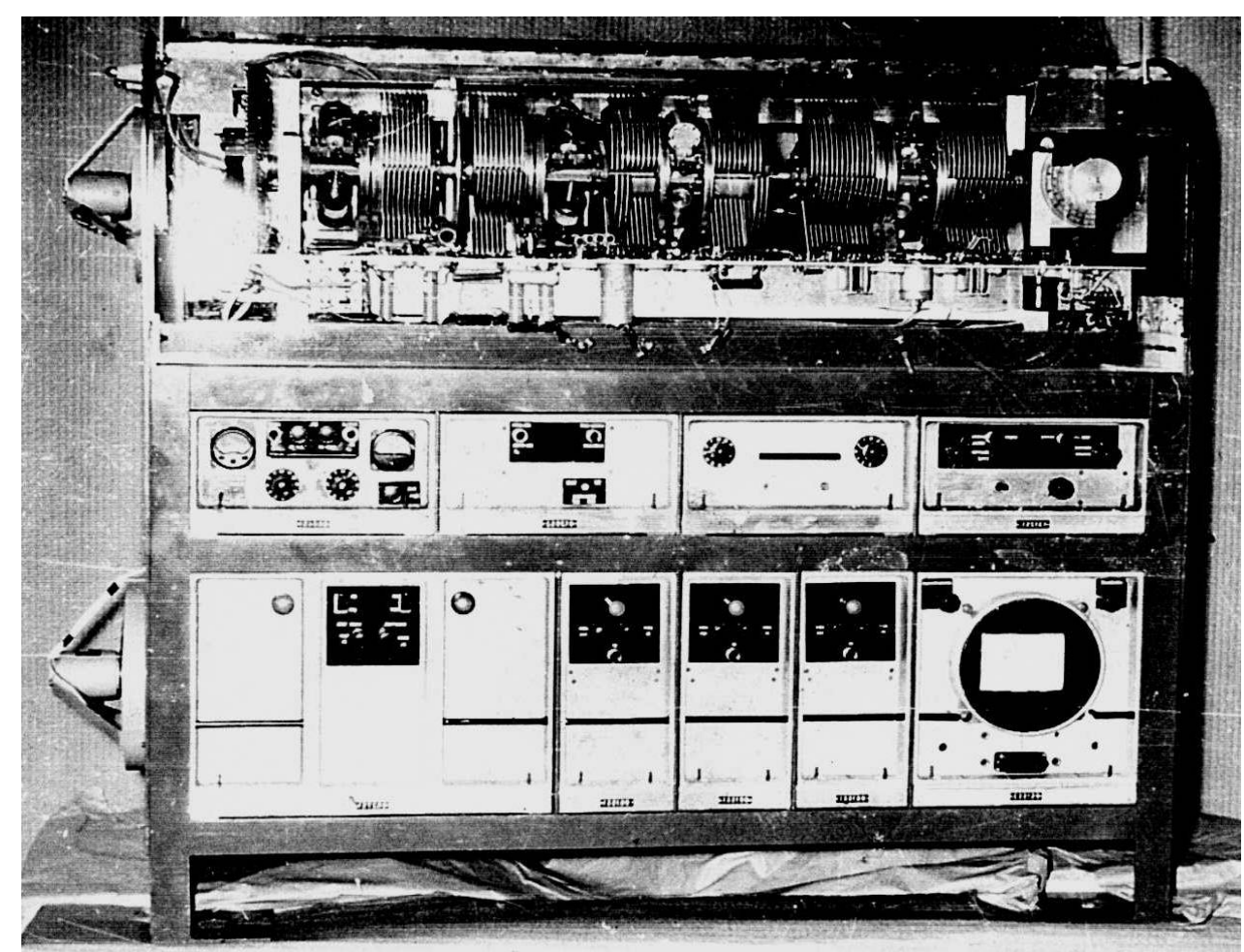

Fig. 1. Panorama-Ionosonde.

With two Ionosondes on a French frigate, sailing in May 1954 to Bergen in Norway, the Panorama-Ionosonde data, taken during a total solar eclipse under good ionospheric conditions, proved without a doubt, that the E- and F1-layer ionization follows the solar occultation without delay (Bibl and Delobeau, 1956) This finding, important for IRI, increased the recombination co-efficient in those regions by two orders of magnitude. Sir Edward Appleton remarked in writing after I sent him our report: "Very interesting."

A second solar eclipse took place over Djibouti, then in French Somalia, in 1955. This eclipse was my most frightening, but wonderful, visual experience I ever had, seeing the shadow of the eclipse raising in waves over the vast desert like the flood. Time-compressed movies from the $1 / 2 \mathrm{~min}$ ionogram recordings showed (Bibl, 1962) that the old ionization of the F2 layer stays on unchanged while the F1 ionization disappears during the eclipse and a new F2 ionization is created from the rising F1 ionization in the second half period of the annular eclipse (Fig. 2). Because the solar activity was already higher than the year before, the contribution of the corona to the total radiation from the sun was higher then the $5 \%$ experienced in the 1954 eclipse. In complementing the finding of the prior eclipse, this movie shows that the recombination coefficient in F2 layer heights, even in day time and at the equator, is much smaller than normally assumed.

The movie of the third eclipse over Genoa, Italy, was animated by using the spare camera, synchronized with the sequence of ionograms, for optical observation of the sun through a tiny hole in front of a long carton tube replacing the lens. The picture of the sequential phases of the sun's occultation was then inserted in the ionogram recordings. This eclipse confirmed the findings of the prior eclipses, although its conditions were not as good.

During the trip to Djibouti I achieved another breakthrough. One of Karl Rawer's favorite subjects (Bibl et al., 1959), was ionospheric absorption measurements. They were necessary for making reasonable ionospheric radio wave predictions. To separate deviative (E-region) and nondeviative (D-region) contributions, Karl Rawer invented the "Spider-Web" for the frequency dependent absorption measurements. Five scientists, including Karl Rawer, had to slave every third night on a 12 -h shift. (allowing vacation and travel). At 02:00 a.m. we had to make absorption measurements: $5 \mathrm{~s}$ looking at the oscilloscope screen, $5 \mathrm{~s}$ to write the amplitude of all the echoes down, etc. for $10 \mathrm{~min}$. We did this for several years to determine the variation in ionospheric absorption. (One of my colleagues made completely random entrées).

After installing a new Ionosonde in Djibouti, I explained to the station chief and officer that he had to make absorption measurements. He told me: at 12 o'clock noon, I eat dinner and at 2 o'clock in the night, I sleep. Thus I took a spare oscilloscope and a spare movie camera and recorded the amplitudes on film. After returning to my institute, I could persuade Karl Rawer that film can average and integrate amplitudes better than some scientists' brains. Automatic recording of absorption measurements was approved. 


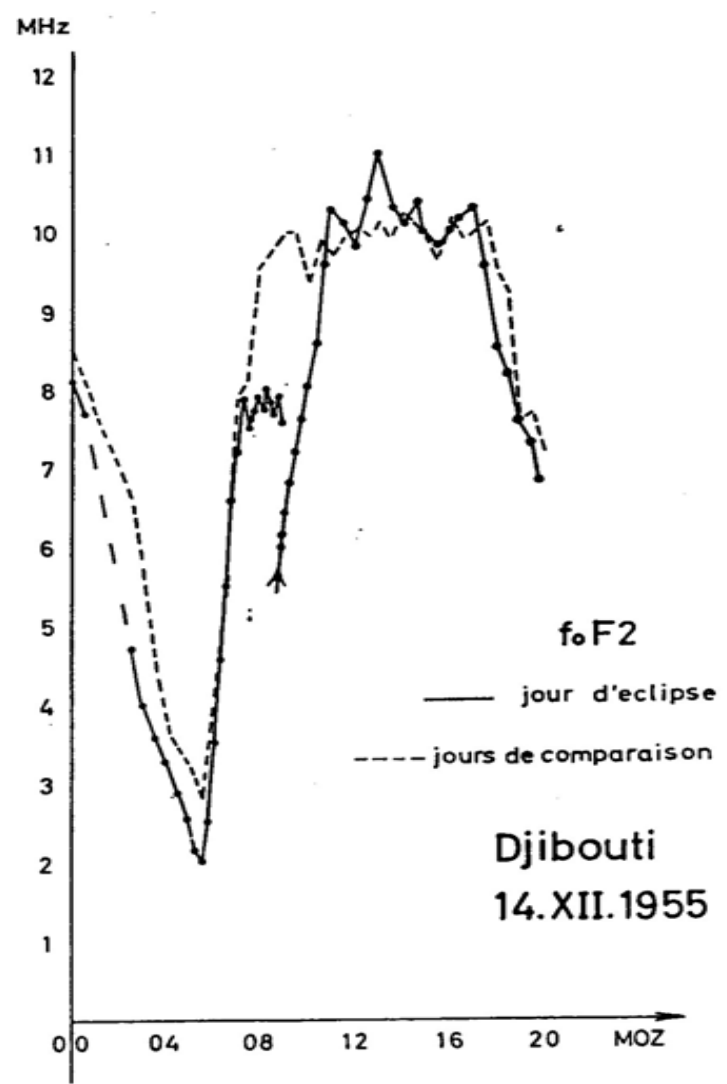

Fig. 2. Zero magnetic dip effect of the eclipse; a new F2-layer is generated independently of the old one.

\section{Ionospheric Dynamics}

Karl Rawer always was interested in the dynamics of the ionosphere. It was already mandatory for his first task of ionospheric predictions. He invented the use of quartiles and deciles to cover the substantial variability and statistical complexity of the ionosphere (Rawer,1951). I made the dynamics of the ionosphere the subject of my Ph.D. thesis (Bibl, 1964). But we worked even later on the subject using the capabilities of the Panorama-Ionosonde to make movies and to record continuously (Bibl and Rawer, 1959).

In respect to the need for standardization, Karl Rawer and I always were in agreement. Standardization allowed his team to build equipment inexpensively for other institutes. In support of the French communication network overseas, we built ionosondes for three African stations: Dakar, Lwiro, and Djibouti, as well as Nha Tran (Viet Nam) and Kerguelen (Antarctica). In Europe, we re-equipped Dourbes (Belgium), Darmstadt (Germany), and Genoa (Italy), in addition to our own station, first in Neuershausen and then in Breisach. This made the European network of ionosondes, left over from the geophysical year, the densest in the world.

In addition, we built a ground backscatter array of 12 rhombus antennas, connected in sequence to three high power fixed frequency transmitters. With the first continuous direct color recordings, we could monitor continuously the ionosphere in an area of $2000 \mathrm{~km}$ radius around the Breisach

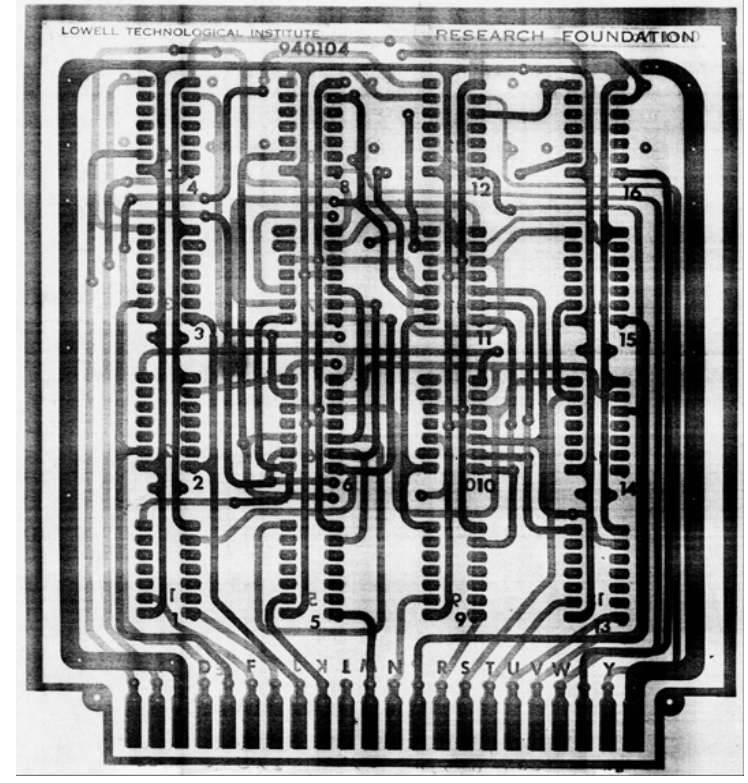

Fig. 3. Digital Memory card with $4 \times 16$ bits (1968).

station. Direct echoes from a distance of $500 \mathrm{~km}$, arriving from the south, led to the discovery of a big hole in the ionosphere. Ionospheric maps, drawn from the dense network of stations, shows that this condition is relatively frequent, at least ten percent of the time (Bibl, 1964). It also verified the importance of the ionospheric station Sottens in Switzerland, which formerly was considered poor quality because sometimes it showed low critical frequencies.

Because I was unwilling to work for the German secret service and since any other interest in ionospheric research faded in Germany, I emigrated to the USA. How little did I imagine that the US, after the murder of President Kennedy, would become as belligerent as Germany was before?

\section{Lowell: Center for Atmospheric Research}

When I came to Lowell, MA, my first tasks were to complete an ionospheric drift station (Pfister and Bibl, 1972) and a sophisticated satellite signal recording station using multi-frequency dispersive Doppler and Faraday methods (Reinisch, 1970). These were the only subjects where I had no experience because my former colleague Ewald Harnischmacher had covered the first and Dr. Hess the second. After completion of the respective measuring equipment within a year, I thought I knew it all. Now I see that I know only ten percent of what I need to know to be successful. So fast is progress that I cannot keep up with it at all. It is absolutely necessary now to work in teams. For the first digital ionosonde, I developed digital frequency synthesis and a digital integrator with a comparator and a forward/reverse counter. Its printed circuit card with a $4 \times 16$ bit memory is presented as Fig. 3. But the first Digisonde, which was used successfully, already required co-workers specialized in programming and computers (Bibl and Reinisch, 1978). 


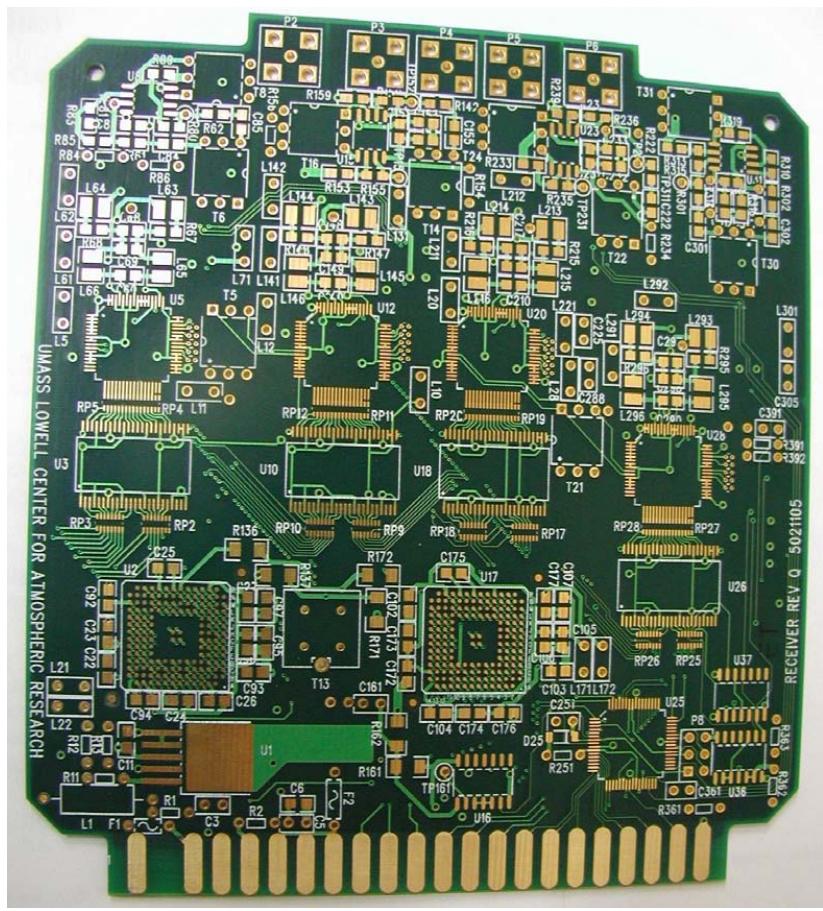

Fig. 4. Digital Receiver card replacing 16 analog cards of same size.

Completing Karl Rawer's legacy in helping other institutes to obtain the most advanced equipment and to promote international co-operation, we have built more than 70 Digisondes used everywhere in the world (Reinisch et al., 1997), one even in space (Reinisch et al., 2000).

Now, after 60 years, we are working on digital transmitters and receivers. They allow any shape for the pulse we want. For the transmitter pulse I have chosen a one-half sine pulse, for reasons explained below. All ionosondes I have designed have analog tuning on the front end because they should work under strongest interference conditions. For the first Digisonde I followed a recommendation by B. W. Reinisch to use the same circuit with switches for transmission first and then for reception. This scheme only works because the receiver was a Gaussian filter and could recover completely from the transmitter pulse very quickly. Even the digital receiver will have digital tuning in front with a bandwidth larger than the pulse to accommodate four adjacent frequencies. The Digital Receiver card (Fig. 4) will replace 16 analog card of the same size. This card has inputs and digitizers for four antennas. The digitizer outputs go to digital inputs of two Greychips. Each Greychip mixes the data digitally with a different frequency. With single-line half-cycle complex spectrum analysis of the received pulse, amplitudes and absolute phase differences of two frequencies are simultaneously analyzed, measuring dispersion or precision group height. Digital cleaning of coherent interferers (Bibl, 2000) and digital extraction of two frequencies from a single pulse will speed up the Digisonde frequency scan to make again $1 / 2$ min ionograms, but with information content orders of magnitude higher than the analog ionosondes.

\section{Conclusion}

In trying to follow the professional ethics of my mentor, Professor Karl Rawer, although I don't have his range of capabilities, I have established a pattern of work that creates new knowledge in our field and allows other institutes and colleagues the same.

\section{References}

Bibl, K.: Zur Dynamik der Ionosphäre, Zeitschr. f. Geoph., Sonderheft 1, 1-33, 1958.

Bibl, K.: Does magnetic field aligned displacement govern the F2region?, Ann. Geophysicae, 18, 294-297, 1962.

Bibl, K.: The detection of an important anomaly in the F-region ionization over central Europe, Ann. Geophysicae, 20, 447-453, 1964;

Bibl, K.:Die Sonnenfinsternis vom 14. December 1955 bei Djibouti, Kleinheubacher Berichte, 97-100, 1958.

Bibl, K.: Patent application \# 09/728,846, 2000.

Bibl, K. and Delobeau, F.: Ionosphärische Beobachtungen während der totalen Sonnenfinsternis vom 30. Juni 1954, Zeitschr. f. Geophys., 21, 215-228, 1956.

Bibl, K. and Rawer, K.: Travelling disturbances originating in the outer ionosphere, J. Geoph. Res. 64, 2232-2238, 1959.

Bibl, K. and Reinisch, B. W.: The Universal Digital Ionosonde, Radio Science 13, 619-529, 1978.

Bibl, K., Paul, A., and Rawer, K.: Die Frequenzabhängigkeit der ionosphärischen Absorption, JATP 16, 324-339, 1959.

Huber, L. and Rawer, K.: Zur Frage des besten Impulsempfängers, AEÜ 4, 475-484 and 523-526, 1950.

Pfister, W. and Bibl, K.: A modernized technique for ionospheric drift with spectrum analysis, Space Res. XII, 975-982, 1972.

Rawer, K.: Ausbreitungsvorhersage für Kurzwellen mit Hilfe von Ionosphärenbeobachtungen, AEÜ 5, 154-167, 1951.

Reinisch, B. W.: Second Order Phase Path Calculations for the Trans-ionospheric Propagation, Proc. of the Symposium on the Future Application of Satellite Beacon Experiments, Lindau/Harz, W. Germany, 28-1 to 28-6, 1970.

Reinisch, B. W. and Sales, G. S.: Ionospheric sounding support of OTH Radar, Radio Sci. 13, 1681-1694, 1997.

Reinisch, B. W., Haines, D. M., Bibl, K., Cheney, G. P., Galkin, I. A., Huang, X., Myers, S. H., Sales, G. S., Benson, R. F., Fung, S. F., Green, J. L., Boardsen, S., Taylor, W. L., Bougeret, J.L., Manning, R., Meyer-Vernet, N., Moncuquet, M., Carpenter, D. L., Galagher, D. L., and Reif, P.: The Radio Plasma Imager Investigation on the Image Spacecraft, Space Science Rev. 91, 319-359, 2000. 